\title{
Determinants of diabetic retinopathy in Tikur Anbessa Hospital, Ethiopia: a case-control study
}

\author{
Kalid Seid ${ }^{1 *}$ (D), Temamen Tesfaye ${ }^{2}$, Admasu Belay $^{2}$ and Hayat Mohammed ${ }^{3}$
}

\begin{abstract}
Background: Diabetic retinopathy is the most frequent complication of Diabetes Mellitus and remains the leading cause of preventable blindness. However, there are limited studies on the determinants of diabetic retinopathy in the study area as well in Ethiopia. Hence, this study aimed to assess the determinants of diabetic retinopathy among diabetic patients at Tikur Anbessa Hospital.

Methods: An institution-based unmatched case-control study design was conducted at Tikur Anbessa Hospital from May 11 to June 26, 2020. Diabetic patients who developed retinopathy within 2 years were cases in the study. Patients who were free of retinopathy were controls in this study. Data were collected using a pretested intervieweradministered questionnaire, Topcon retinal examination, and a record review. The collected data were entered into Epi Data version 3.1 software, and analyzed using SPSS version 25. Binary logistic regression analysis was used to assess the determinants of diabetic retinopathy.

Results: A total of 282 patients (142 cases and 140 controls) were included in the study. The mean age ( \pm Standard deviation) for the cases and the controls were $50.6($ SD: \pm 18.7$)$ and 44.9 (SD: \pm 17.65$)$ respectively. Patients who had a glucometer at home ( $\mathrm{AOR}=0.048 ; 95 \% \mathrm{Cl}: 0.005-0.492)$, exercise adherence (AOR $=0.075 ; 95 \% \mathrm{Cl}: 0.007-0.84)$, diabetes duration $<5$ years ( $A O R=0.005 ; 95 \% \mathrm{Cl}: 0.00-0.10)$ and $5-10$ years ( $\mathrm{AOR}=0.041 ; 95 \% \mathrm{Cl}: 0.003-0.57$ ), health information on diabetic complications ( $\mathrm{AOR}=0.002 ; 95 \% \mathrm{Cl}: 0.00-0.042)$ and appointments every month $(\mathrm{AOR}=0.004$; 95\% Cl: $0.00-0.073$ ) and every 3 months ( $\mathrm{AOR}=0.022 ; 95 \% \mathrm{Cl}: 0.002-0.23$ ) were less likely to develop diabetic retinopathy. Participants who had poor glycemic control $(\mathrm{AOR}=19.9 ; 95 \% \mathrm{Cl}$ : 2.34-168.69), systolic hypertension ( $\mathrm{AOR}=23.4$; 95\% Cl: 2.56-215.36) and nephropathy ( $\mathrm{AOR}=17.85 ; 95 \% \mathrm{Cl}: 2.01-158.1)$, had a higher risk of developing diabetic retinopathy.

Conclusions: Patients who had a glucometer at home, exercise adherence, diabetes duration $<10$ years, health information on diabetic complications, and frequent follow-up had a preventive role. However, poor glycemic control, systolic hypertension, and nephropathy increase the risk of diabetic retinopathy. A concerted effort should be made to improve the health status of patients with Diabetes Mellitus, with particular emphasis on lifestyle modification practices to prevent diabetic retinopathy.
\end{abstract}

Keywords: Diabetic retinopathy, Determinants, Case-control, Ethiopia

*Correspondence: Kalidseid7@gmail.com

1 Department of Nursing, College of Health Science, Mizan-Tepi University, P.O. Box: 260, Mizan, SNNPR, Ethiopia

Full list of author information is available at the end of the article

\section{Background}

With the increasing prevalence of diabetes globally, diabetic retinopathy (DR) has become a severe threat to public health [1]. Globally, DR constitutes $5 \%$ of all blindness and affects 2 million people [2]. It is the most frequent complication of diabetes and remains the leading cause of preventable blindness $[3,4]$. In addition, original author(s) and the source, provide a link to the Creative Commons licence, and indicate if changes were made. The images or other third party material in this article are included in the article's Creative Commons licence, unless indicated otherwise in a credit line to the material. If material is not included in the article's Creative Commons licence and your intended use is not permitted by statutory regulation or exceeds the permitted use, you will need to obtain permission directly from the copyright holder. To view a copy of this licence, visit http://creativecommons.org/licenses/by/4.0/. The Creative Commons Public Domain Dedication waiver (http://creativeco mmons.org/publicdomain/zero/1.0/) applies to the data made available in this article, unless otherwise stated in a credit line to the data. 
loss of productivity and quality of life in patients with DR results in additional socioeconomic burdens on the community [5].

Retinopathy is positively associated with all-cause mortality among adults, especially those with diabetes, and has also been shown to correlate with an increased risk of cardiovascular events [6]. Patients with DR had significantly worse scores on all scales of quality of life and life satisfaction than those without DR [7].

A global population census showed that of more than 32.4 million blind and 191 million visually impaired people, 0.8 million were blind, and 3.7 million were visually impaired due to DR [8]. Sadly, DR affects $30.2-31.6 \%$ of diabetes patients in Africa, especially in Sub-Saharan countries [9], and the presence and progression of DR are associated with significant increases in health care costs [10]. Yearly eye examinations reduce blindness by $>95 \%$; however, compliance with annual eye examinations remains $50 \%$ or less in many areas [11]. In Ethiopia, the overall prevalence of DR among patients with DM is $19.48 \%$ [12]. The presence and severity of complications related to DR in the country are steadily increasing causes of premature death and disability [13].

The major risk factors (hyperglycemia, hyperlipidemia, and hypertension) have been extensively studied, and are strongly associated with DR [14, 15]. However, there is considerable variation in the consistency, pattern, and strength of these risk factors [4]. Some studies indicate that family history, prolonged DM duration, and glycemic control are well-established risk factors for DR [16, 17]. However, further studies are needed to confirm this relationship [18]. Therefore, apart from these factors, it is also essential to examine the effect of institutional factors on DR, which has not been well addressed by other quantitative studies.

In addition, there are limited studies on the determinants of diabetic retinopathy in the study area as well in Ethiopia. Moreover, the effects of significant determinant factors of DR are still discrepant and inconclusive among the Ethiopian population, which needs to be evaluated. Therefore, this study aimed to assess the determinants of DR among patients with Diabetes Mellitus at Tikur Anbessa Hospital, Addis Ababa, Ethiopia.

\section{Methods}

\section{Study design, setting, and population}

The institution-based unmatched case-control study design was conducted at the outpatient diabetic clinic of Tikur Anbessa Hospital, Addis Ababa, Ethiopia, from May 11 to June 26, 2020. The hospital receives approximately 400,000 patients referred from across Ethiopia annually. It is the largest teaching hospital in Ethiopia and provides a tertiary level referral treatment with $24 \mathrm{~h}$ emergency services, and it has different specialty clinics that provide follow-up services. The Diabetic clinic is the largest referral clinic for DM in the country, and provides services for more than 300 people per week regularly. Currently, there are more than 7000 diabetes mellitus patients on follow-up in the clinic.

For this particular study, the source population was diabetic patients on follow-up at the Tikur Anbessa Hospital diabetic clinic. The cases were diabetic patients who developed retinopathy within 2 years. Diabetic retinopathies had a history of diabetic retinopathy on the patient index card and had been diagnosed by ophthalmologists. In contrast, controls were diabetic patients free of retinopathy, which ophthalmologists decided during the data collection period. All adults ( $>14$ years) with DM who had no severe mental problems participated in the study.

\section{Sample size and sampling procedure}

The sample size was determined using EPI-Info 7.1 statistical software. The assumptions for the sample size calculation were as follows: the proportion of poor glycemic control among cases [19], the minimum detectable odds ratio of 2.7 , a confidence level of $95 \%$, a power of $80 \%$, a case to control the ratio of $1: 1$, and non-response rate of $5 \%$ which gives a final sample size of 284 (142 cases and 142 controls). Simple random sampling was used to recruit participants. The card numbers of the identified participants were coded for the cases and controls. After the codes of cases and controls, 223 cases and 1652 controls were entered into a computer-generated random number. A hundred forty-two cases and 142 controls were randomly selected.

\section{Data collection tools and procedures}

The cases and controls were identified, and confirmed by physicians and ophthalmologists. For data collection, an interviewer-administered questionnaire, Topcon retinal examination, and record review were used. We conducted record reviews of patients with diabetes to identify cases and controls from records using a checklist. Cases and controls were recorded using the identification numbers. For the controls, an additional Topcon retinal examination was performed by an ophthalmologist. Retinal photographs were taken with a Topcon camera in a well darken room. Using photographic images, diabetic retinopathy was classified as present or absent in each eye. The ophthalmologist performed the classification, which was audited by a physician in the clinic during follow-up. After differentiating between cases and controls, data were collected from record review/patient identification cards and interviews with the study participants. Data were collected by two trained BSc nurses and 1 MSc nurse as supervisors. The questionnaire was 
prepared in English, translated to the Amharic language, and then back-translated to English by experts.

The questionnaire has four parts adapted from a study conducted at the Tikur Anbessa Hospital [20, 21]. It includes socio-demographic factors, behavioral factors, clinical factors, and institutional factors. The knowledge part has 07 items, and the attitude part has 05 items adopted from a study conducted in Saudi Arabia [22]. The Knowledge and attitude parts were tested for reliability with Cronbach alpha of 0.76 and 0.81 , respectively. The trusting relationship was measured using the Revised Health Care Relationship (HCR-R) Trust Scale, which was tested for reliability with a Cronbach alpha of 0.91 [23]. For clinical factors, three results were obtained near the diagnosis of diabetic retinopathy for cases and near to data collection for free of diabetic retinopathy from patient medical records, and the average result was recorded.

\section{Measurements}

An ophthalmologist measured diabetic retinopathy with any characteristic lesion on retinal camera examination, microaneurysms, hemorrhages, exudation, cotton wool spots, and/or new vessels [24]. Glycemic control was measured using fasting blood sugar (FBS). A DM patient with $<70 \mathrm{mg} / \mathrm{dl}$ and $>126 \mathrm{mg} / \mathrm{dl}$ average fasting blood sugar level of the last three records was coded as poor glycemic control, otherwise good glycemic control [25]. Body mass index was used to define underweight (BMI<18.5), normal (18.5-24.9), overweight (25.0-30.0), and obesity $(\mathrm{BMI}>30)$ in adults [26]. Hypertension was defined as systolic blood pressure (SBP) $\geq 140 \mathrm{mmHg}$, diastolic blood pressure $(\mathrm{DBP}) \geq 90 \mathrm{mmHg}$ or current use of antihypertensive medication. Two Measurements were taken from the left-arm 5 min apart in the sitting position. The average was recorded using a mercury sphygmomanometer with a cuff deflation rate of $2 \mathrm{mmHg}$ [25]. Hyperlipidemia is defined as a total cholesterol level $>200 \mathrm{mg} / \mathrm{dl}$ or triglyceride level $>150 \mathrm{mg} / \mathrm{dl}$ [25]. Medication adherence was assessed if the patients took all their anti-diabetic medications in the last 7 days $[27,28]$. Adherence to blood glucose testing at home was measured if the patient measured their blood glucose once a week $[27,28]$. Adherence to diet was measured if the patient followed the recommended diet for more than 3 days in the last 7 days [27, 28]. Adherence to exercise was measured if the patient performed a 30-min activity prescribed by a physician for more than 3 days in the last 7 days $[27,28]$. Alcohol consumption history was measured if the patient reported drinking any alcohol within the last 12 months [27, 28]. A positive attitude is defined as answered correctly more than the $50 \%$ score of attitude questions otherwise negative attitude
[22]. 'Excellent' grade of knowledge if the score is higher than $75 \%$; 'Good' if it is between 50 to $75 \%$, and; 'Poor' if it is less than $50 \%$ [22]. A good trusting relationship with healthcare providers was measured as patients who answered correctly more than or equal to the mean score on the Revised Health Care relationship (HCR) trust scale, otherwise poor trusting relationships with healthcare providers [23].

\section{Data processing and analysis}

The data were coded and entered into Epi-data 3.1, and exported to SPSS version 25 for analysis. Descriptive statistics such as frequency, percentage, standard deviation, and mean were used to summarize the data. In the current study, cases were coded as 1 , and the controls were coded as 0 . The exposure variables associated with DR were identified using a bivariate logistic regression analysis. Exposure variables with a $p$-value $<0.25$ were considered for final multivariable logistic regression analysis. Statistical significance was set at $p$-value $<0.05$, and exposure variables with a $p$-value $<0.05$ were considered as determinants of DR. Model fitness was checked by Hosmer and Lemeshow $(P$-value $=0.698)$, omnibus likelihood test ( $P$-value 0.00$)$ with $96 \%$ model accuracy. The adjusted odds ratio (AOR) with a $95 \%$ confidence interval (CI) was computed to determine the strength of the association between the variables of interest.

\section{Results}

\section{Socio-demographic characteristics}

From a sample of 284 (142 cases and 142 controls), 282 (142 cases and 140 controls) participated in this study with a response rate of $99.3 \%$. The mean age ( \pm Standard deviation) for the cases and the controls had 50.6 (SD: \pm 18.7$)$ and 44.9 (SD: \pm 17.65$)$, respectively. Eighty $(56.3 \%)$ cases and $60(42.9 \%)$ of the controls were male. Ninety-one $(64.1 \%)$ of the cases and $86(61.4 \%)$ of the controls were married. Eighty-five (59.9\%) cases and $82(58.6 \%)$ controls had urban residences. The majority $(68.3 \%)$ of the cases and $93(66.4 \%)$ of the control's monthly income had more than 1500 Ethiopian Birr (ETB) (Table 1).

\section{Behavioral related characteristics}

The majority of participants, $112(78.9 \%)$ cases and $84(60.0 \%)$ controls, had no glucometer at home. Most cases $(90.1 \%)$ and 101 controls $(72.1 \%)$ did not have a diet plan. Most cases (88.7\%) and 90 controls (64.3\%) did not adhere to the exercise regimen. More than half (52.1\%) of the cases had poor knowledge of diabetic retinopathy, whereas $66(47.1 \%)$ of the controls had good knowledge. Regarding attitude, 94(66.2\%) of the cases and 110(78.6\%) 
Table 1 Socio-demographic characteristics of diabetic patients at Tikur Anbessa Hospital, Ethiopia, $2020(n=282)$

\begin{tabular}{|c|c|c|c|}
\hline Variable & Category & $\begin{array}{l}\text { Cases } \\
\text { Number (\%) }\end{array}$ & $\begin{array}{l}\text { Controls } \\
\text { Number (\%) }\end{array}$ \\
\hline \multirow[t]{2}{*}{ Age } & $<60$ years & $102(71.8)$ & $116(82.8)$ \\
\hline & $\geq 60$ years & $40(28.2)$ & $24(17.2)$ \\
\hline \multirow[t]{2}{*}{ Sex } & Male & $80(56.3)$ & $60(42.9)$ \\
\hline & Female & $62(43.7)$ & $80(57.1)$ \\
\hline \multirow[t]{4}{*}{ Marital Status } & Single & $16(11.3)$ & $37(26.4)$ \\
\hline & Married & $91(64.1)$ & $86(61.4)$ \\
\hline & Divorced & $19(13.4)$ & $10(7.1)$ \\
\hline & Widowed & $16(11.3)$ & $7(5.0)$ \\
\hline \multirow[t]{2}{*}{ Residence } & Urban & $85(59.9)$ & $82(58.6)$ \\
\hline & Rural & $57(40.1)$ & $58(41.4)$ \\
\hline \multirow[t]{6}{*}{ Educational Status } & $\begin{array}{l}\text { Unable to read and } \\
\text { write }\end{array}$ & $17(12.0)$ & $15(10.7)$ \\
\hline & Read and write & $24(16.9)$ & $17(12.1)$ \\
\hline & Primary & $18(12.7)$ & $15(10.7)$ \\
\hline & Secondary & $23(16.2)$ & $20(14.3)$ \\
\hline & Diploma & $30(21.1)$ & $34(24.3)$ \\
\hline & Degree and above & $30(21.1)$ & 39 (27.9) \\
\hline \multirow{6}{*}{$\begin{array}{l}\text { Occupational } \\
\text { Status }\end{array}$} & Farmer & $18(12.7)$ & $12(8.6)$ \\
\hline & $\begin{array}{l}\text { Government } \\
\text { Employee }\end{array}$ & $36(25.4)$ & $65(46.4)$ \\
\hline & Self-employee & $24(16.9)$ & 19 (13.6) \\
\hline & Private business & $36(25.4)$ & $27(19.3)$ \\
\hline & Non-employee & $22(15.5)$ & $7(5.0)$ \\
\hline & Student & $6(4.2)$ & $10(7.1)$ \\
\hline \multirow[t]{2}{*}{ Monthly Income } & $\leq 1500$ ETB & $45(31.7)$ & 47 (33.6) \\
\hline & $>1500$ ETB & $97(68.3)$ & $93(66.4)$ \\
\hline
\end{tabular}

of the controls had positive attitudes toward diabetic retinopathy (Table 2).

\section{Clinical related characteristics}

Eighty-six (60.6\%) of cases and $84(60.0 \%)$ controls had Type II diabetes. More than half (52.1\%) of cases had more than 15 years since diabetes diagnosis, but 82 (58.6\%) of controls had less than 5 years. Regarding glycemic control, 109(76.8\%) of cases had poor glycemic control, while $107(76.4 \%)$ of the controls had good glycemic control. Eighty-seven (61.3\%) cases and 119 (85.0\%) controls had no history of nephropathy. More than Onethird of the 56(39.4\%) cases and 32(22.9\%) of the controls had obesity (Table 3 ).

\section{Institutional related characteristics}

One hundred and nineteen $(83.8 \%)$ of the cases did not receive health information on diabetic complications, whereas $108(77.1 \%)$ of the controls had to obtain health information. Ninety-six (67.6\%) cases and one-tenth $(14.3 \%)$ of the controls were appointed every 6 months.
Table 2 Behavioral related characteristics of diabetic patients at Tikur Anbessa Hospital, Ethiopia, $2020(n=282)$

\begin{tabular}{llll}
\hline Variable & Category & $\begin{array}{l}\text { Cases } \\
\text { Number (\%) }\end{array}$ & $\begin{array}{l}\text { Controls } \\
\text { Number (\%) }\end{array}$ \\
\hline Glucometer at home & Yes & $30(21.1)$ & $56(40.0)$ \\
& No & $112(78.9)$ & $84(60.0)$ \\
Adherence to blood & Adhered & $11(36.7)$ & $26(46.4)$ \\
glucose measurement & Not adhered & $19(63.3)$ & $30(53.6)$ \\
at home & Yes & $14(9.9)$ & $39(27.9)$ \\
Diet Plan & No & $127(90.1)$ & $101(72.1)$ \\
Adherence to diet & Adhered & $2(14.3)$ & $11(28.2)$ \\
& Not adhered & $12(85.7)$ & $28(71.8)$ \\
Medication adherence & Adhered & $94(66.2)$ & $97(69.3)$ \\
& Not adhered & $48(33.8)$ & $43(30.7)$ \\
Exercise adherence & Adhered & $16(11.3)$ & $50(35.7)$ \\
Alcohol & Not adhered & $126(88.7)$ & $90(64.3)$ \\
& Yes & $54(38.0)$ & $28(20.0)$ \\
Number of bottles per day & No & $88(62.0)$ & $112(80.0)$ \\
& $\leq 2$ bottle & $30(55.6)$ & $17(60.7)$ \\
& $>2$ bottles & $24(44.4)$ & $11(39.3)$ \\
Smoking & Yes & $30(21.1)$ & $37(26.4)$ \\
Attitude toward DR & No & $112(78.9)$ & $103(73.6)$ \\
Number of packets per & $<1$ packet & $25(83.3)$ & $28(75.7)$ \\
day & $\geq 1$ packet & $5(16.7)$ & $9(24.3)$ \\
Knowledge of DR & Poor & $74(52.1)$ & $52(37.1)$ \\
& Good & $55(38.7)$ & $66(47.1)$ \\
& Excellent & $13(9.2)$ & $22(15.7)$ \\
& Negative & $48(33.8)$ & $30(21.4)$ \\
& $94(66.2)$ & $110(78.6)$ \\
\hline
\end{tabular}

Regarding trusting relationships with health care providers (HCPs), the majority (83.18\%) of cases and $123(87.9 \%)$ of the controls had a good trusting relationship (Table 4).

\section{Determinants of diabetic retinopathy}

In bivariate analysis, sex, presence of glucometer at home, diet plan, exercise adherence, alcohol consumption, knowledge of diabetic retinopathy, attitude toward diabetic retinopathy, duration of DM, glycemic control, systolic hypertension, creatinine level, hyperlipidemia, neuropathy, nephropathy, health information on diabetic complications and frequency of visits were found to be significantly associated with diabetic retinopathy. In multivariable logistic regression analysis, glucometer at home, exercise adherence, duration of diabetes, poor glycemic control, systolic hypertension, nephropathy, health information on diabetic complications, and frequency of visits were found to be independent determinants of diabetic retinopathy.

Patients who had a glucometer at home were $95.2 \%$ $(\mathrm{AOR}=0.048$; 95\% CI: 0.005-0.492) less likely to develop 
Table 3 Clinical related characteristics of diabetic patients at Tikur Anbessa Hospital, Ethiopia, 2020 ( $n=282)$

\begin{tabular}{|c|c|c|c|}
\hline Variable & Category & $\begin{array}{l}\text { Cases } \\
\text { Number (\%) }\end{array}$ & $\begin{array}{l}\text { Controls } \\
\text { Number (\%) }\end{array}$ \\
\hline \multirow[t]{2}{*}{ Type of DM } & Type I & $56(39.4)$ & $56(40.0)$ \\
\hline & Type II & $86(60.6)$ & $84(60.0)$ \\
\hline \multirow[t]{4}{*}{ Duration of DM } & $<5$ years & $12(8.5)$ & $82(58.6)$ \\
\hline & $5-10$ years & $26(18.3)$ & $31(22.1)$ \\
\hline & $11-15$ years & $30(21.1)$ & $15(10.7)$ \\
\hline & $>15$ years & $74(52.1)$ & $12(8.6)$ \\
\hline \multirow[t]{2}{*}{ Family history of DM } & Yes & $42(29.6)$ & $43(30.7)$ \\
\hline & No & $100(70.4)$ & $97(69.3)$ \\
\hline \multirow[t]{2}{*}{ Glycemic control } & Good & $33(23.2)$ & $107(76.4)$ \\
\hline & Poor & $109(76.8)$ & $33(23.6)$ \\
\hline \multirow[t]{2}{*}{ Hemoglobin level } & $<11 \mathrm{mg} / \mathrm{dl}$ & $38(26.8)$ & $31(22.1)$ \\
\hline & $\geq 11 \mathrm{mg} / \mathrm{dl}$ & $104(73.2)$ & $109(77.9)$ \\
\hline \multirow[t]{2}{*}{ SBP } & $<140 \mathrm{mmHg}$ & $40(28.2)$ & $116(82.9)$ \\
\hline & $\geq 140 \mathrm{mmHg}$ & $102(71.8)$ & $24(17.1)$ \\
\hline \multirow[t]{2}{*}{ DBP } & $<90 \mathrm{mmHg}$ & $84(59.2)$ & 89 (63.6) \\
\hline & $\geq 90 \mathrm{mmHg}$ & $58(40.8)$ & $51(36.4)$ \\
\hline \multirow[t]{3}{*}{ BUN } & $<6 \mathrm{mg} / \mathrm{dl}$ & $47(33.1)$ & $23(16.4)$ \\
\hline & $6-31 \mathrm{mg} / \mathrm{dl}$ & 69 (48.6) & $96(68.6)$ \\
\hline & $>31 \mathrm{mg} / \mathrm{dl}$ & $26(18.3)$ & $21(15.0)$ \\
\hline \multirow[t]{2}{*}{ Creatinine } & $>1.2 \mathrm{mg} / \mathrm{dl}$ & $73(51.4)$ & $44(31.4)$ \\
\hline & $\leq 1.2 \mathrm{mg} / \mathrm{dl}$ & $69(48.6)$ & $96(68.6)$ \\
\hline \multirow[t]{2}{*}{ Hyperlipidemia } & Yes & $65(45.8)$ & $28(20.0)$ \\
\hline & No & $77(54.2)$ & $112(80.0)$ \\
\hline \multirow[t]{2}{*}{ Neuropathy } & Yes & $41(28.9)$ & $25(17.9)$ \\
\hline & No & $101(71.1)$ & $115(82.1)$ \\
\hline \multirow[t]{2}{*}{ Nephropathy } & Yes & $55(38.7)$ & $21(15.0)$ \\
\hline & No & $87(61.3)$ & $119(85.0)$ \\
\hline \multirow[t]{4}{*}{ Treatment modality } & Injection/insulin & $54(38.0)$ & 55 (39.3) \\
\hline & Oral hypoglycemic & $65(45.8)$ & $52(37.1)$ \\
\hline & $\begin{array}{l}\text { Both insulin and } \\
\text { oral hypogly- } \\
\text { cemic }\end{array}$ & $16(11.3)$ & $15(10.7)$ \\
\hline & Diet or exercise & $7(4.9)$ & $18(12.9)$ \\
\hline \multirow{2}{*}{$\begin{array}{l}\text { History of cataract } \\
\text { surgery }\end{array}$} & Yes & $16(11.3)$ & $11(7.9)$ \\
\hline & No & $126(88.7)$ & $129(92.1)$ \\
\hline \multirow[t]{4}{*}{ BMI } & Underweight & $18(12.7)$ & $14(10.0)$ \\
\hline & Normal & $48(33.8)$ & $79(56.4)$ \\
\hline & Overweight & $20(14.1)$ & $15(10.7)$ \\
\hline & Obesity & $56(39.4)$ & 32 (22.9) \\
\hline
\end{tabular}

DR than diabetic patients who had no glucometer at home. The proportion of respondents who adhered to exercise was 92.5\% (AOR $=0.075$; 95\% CI: 0.007-0.84) less likely to develop DR than diabetic patients who did not adhere to exercise. Patients with diabetes duration less than 5 years were $99.5 \%(\mathrm{AOR}=0.005$; $95 \% \mathrm{CI}$ : $0.00-0.10)$ less likely to develop DR, and those between
5-10 years were $95.9 \%(\mathrm{AOR}=0.041 ; 95 \% \mathrm{CI}: 0.003-$ 0.57 ) less likely to develop DR than patients whose diabetes duration was more than 15 years. Individuals with poor glycemic control were 19 times $(\mathrm{AOR}=19.9$; $95 \%$ CI: 2.34-168.69) more likely to develop DR than those with good glycemic control.

Systolic hypertension was approximately 23 times $(\mathrm{AOR}=23.4 ;$ 95\% CI: 2.56-215.36) more likely to develop DR than their counterparts. Respondents who had nephropathy were approximately 17 times $(\mathrm{AOR}=17.85$; 95\% CI: 2.01-158.1) more likely to develop DR than those who had no previous history of nephropathy. Patients who received health information on diabetic complications were $99.8 \%(\mathrm{AOR}=0.002 ; 95 \% \mathrm{CI}: 0.00-0.042)$ less likely to develop DR than those who did not receive health information. Respondents who appointed every month had 96.6\% (AOR $=0.004$; 95\% CI: 0.00-0.073) less likely to develop DR, and those patients who appointed every 3 months had $97.8 \%$ (AOR $=0.022$; 95\% CI: 0.002 $0.23)$ less likely to develop DR compared to those who appointed for a visit every 6 months (Table 5).

\section{Discussion}

In this case-control study of Diabetes Mellitus patients managed in Tikur Anbessa Hospital, several determinant factors for the occurrence of diabetic retinopathy were identified. In particular, patients who had a glucometer at home, exercise adherence, diabetes duration $<5$ years and 5-10 years, health information on diabetic complications and being appointed every month and every 3 months had a reduced risk of DR. However, those with poor glycemic control, systolic hypertension and nephropathy had an increased risk of DR.

The current study showed that patients who had a glucometer at home had much fewer odds of having DR than those who did not. The possible reasons might be the ability of the patient to individualize their treatment regimen to obtain optimal blood glucose control. This individualized treatment allows for the detection and prevention of hypoglycemia and hyperglycemia. It plays a crucial role in normalizing blood glucose levels, which reduces the risk of long-term diabetic complications [25]. Therefore, maintaining tight control of blood sugar at home is the best way to avoid diabetes complications.

The current study also revealed that the odds of DR were significantly lower among patients who adhered to exercise than among those who did not adhere to exercise. This finding is in line with a case-control study conducted in the United Kingdom, which reported an inverse relationship between the severity of diabetic retinopathy and physical activity [29]. The possible reasons might be that exercise lowers blood glucose levels by increasing the uptake of glucose by body muscles and 
Table 4 Institutional related characteristics of diabetic patients at Tikur Anbessa Hospital, Ethiopia, $2020(n=282)$

\begin{tabular}{|c|c|c|c|}
\hline Variable & Category & $\begin{array}{l}\text { Cases } \\
\text { Number (\%) }\end{array}$ & $\begin{array}{l}\text { Controls } \\
\text { Number (\%) }\end{array}$ \\
\hline \multirow{2}{*}{$\begin{array}{l}\text { Getting health information on diabetic compli- } \\
\text { cation }\end{array}$} & Yes & $23(16.2)$ & $108(77.1)$ \\
\hline & No & $119(83.8)$ & $32(22.9)$ \\
\hline \multirow[t]{2}{*}{ Difficulty in access to a diabetic care } & Yes & $54(38.0)$ & $45(32.1)$ \\
\hline & No & $88(62.0)$ & $95(67.9)$ \\
\hline \multirow[t]{4}{*}{ Type of difficulty } & The functionality of a screening device & $27(50.0)$ & $10(22.2)$ \\
\hline & Distance to the facility & $10(18.5)$ & $11(24.4)$ \\
\hline & Many people in the follow-up clinic & $9(16.7)$ & $10(22.2)$ \\
\hline & Quality of the service & $8(14.8)$ & $14(31.1)$ \\
\hline \multirow[t]{3}{*}{ Frequency of visit appointed } & Every month & $21(14.8)$ & $55(39.3)$ \\
\hline & Every 3 months & $25(17.6)$ & $65(46.4)$ \\
\hline & Every 6 months & $96(67.6)$ & $20(14.3)$ \\
\hline \multirow[t]{2}{*}{ Trusting relationship with $\mathrm{HCP}$} & Good & $118(83.1)$ & $123(87.9)$ \\
\hline & Poor & $24(16.9)$ & $17(12.1)$ \\
\hline
\end{tabular}

improving insulin sensitivity, decreasing the possibility of DR occurrence [25].

The current study found that the odds of DR increased in patients with a longer duration of diabetes. This finding is in line with previous studies conducted worldwide [21, $30-34]$, which reported that diabetes duration $\geq 10$ years is the most significant risk factor for the occurrence of diabetic retinopathy.

Regarding glycemic control, individuals with FBS $<70 \mathrm{Mmg} / \mathrm{dl}$ and $>126 \mathrm{mg} / \mathrm{dl}$ were much more likely to have DR than those with good glycemic control. This finding is consistent with previous studies conducted around the world $[16,30,35-40]$, which reported that high levels of fasting blood glucose and HbA1c were associated with higher grades of retinopathy. This may be due to poor glycemic control, and diabetic blood-retinal barrier breakdown, which induces vascular leakage and macular edema [41].

The odds of DR were significantly higher among patients with systolic hypertension than among those without systolic hypertension. This finding is in line with previous studies conducted worldwide $[20,31,33,36,37$, $40,42]$, which reported that DR increased with a mean systolic $\mathrm{BP} \geq 140 \mathrm{mmHg}$. These findings underline the need for patient education among DM patients regarding the importance of $\mathrm{BP}$ control in preventing blindness from advanced DR.

The current study also revealed that the odds of DR were higher among patients with nephropathy. This finding is consistent with a case-control study conducted in Brazil [30] and Portugal [38], which reported a significant association between nephropathy and diabetic retinopathy. The possible reasons might damage the small blood vessels, which share the same pathogenesis as systemic microvascular dysfunction [43]. Therefore, optimizing blood-sugar control and tightly controlling blood pressure can reduce the risk of developing nephropathy because these diseases share the same pathological changes.

The current study showed that patients who received health information from health care providers about diabetic complications had lower odds of developing DR than those who did not receive health information. The possible reasons might be that when the patient receives health information on diabetic complications during follow-up, the patient's awareness increases with inspiration to adhere to self-management goals [44].

Regarding the frequency of visits, respondents who were appointed every month and every 3 months had much fewer odds of having DR than those appointed for a visit every 6 months. This finding is in line with a cross-sectional study conducted in Addis Ababa, Ethiopia, which reported that participants who visited the diabetes clinic every month had lower odds of developing DR when compared to patients who visited the clinic every 6 months [21]. The possible reasons might be that frequent visits to the clinic enable health professionals and patients to know the progress of the disease and adjust the treatment option as early as possible before the occurrence of severe complications.

The strength of this study was that the case and control criteria were strictly defined to enrich the study for participants at the two extremes of the disease spectrum and minimize misclassification bias. The average baseline measurements for the cases and recent measurements of the controls were recorded. This study also assessed 
Table 5 Multivariable logistic regression analysis of Diabetic Retinopathy in Tikur Anbessa Hospital, Ethiopia, 2020

\begin{tabular}{|c|c|c|c|c|c|c|}
\hline Variable & Category & Cases $(n=142)$ & Control $(n=140)$ & $\operatorname{COR}(95 \% \mathrm{Cl})$ & $\operatorname{AOR}(95 \% \mathrm{Cl})$ & $P$-value \\
\hline \multirow[t]{2}{*}{ Sex } & Male & $80(56.3)$ & $60(42.9)$ & $1.72(1.074-2.75)$ & $3.65(0.47-28.01)$ & 0.213 \\
\hline & Female & $62(43.7)$ & $80(57.1)$ & 1 & 1 & \\
\hline \multirow[t]{2}{*}{ Glucometer at home } & Yes & $30(21.1)$ & $56(40.0)$ & $0.40(0.23-0.68)$ & $0.048(0.005-0.49$ & $0.011^{*}$ \\
\hline & No & 112(78.9) & $84(60.0)$ & 1 & 1 & \\
\hline \multirow[t]{2}{*}{ Diet Plan } & Yes & $14(9.9)$ & $39(27.9)$ & $0.28(0.147-0.55)$ & $0.33(0.032-3.47)$ & 0.357 \\
\hline & No & 127(90.1) & $101(72.1)$ & 1 & 1 & \\
\hline \multirow[t]{2}{*}{ Exercise Adherence } & Adhered & 16(11.3) & $50(35.7)$ & $0.22(0.122-0.42)$ & $0.075(0.007-0.84)$ & $0.036^{*}$ \\
\hline & Not adhered & 126(88.7) & $90(64.3)$ & 1 & 1 & \\
\hline \multirow[t]{2}{*}{ Alcohol } & Yes & $54(38.0)$ & $28(20.0)$ & $2.45(1.43-4.19)$ & $7.70(0.64-92.22)$ & 0.107 \\
\hline & No & $88(62.0)$ & 112(80.0) & 1 & 1 & \\
\hline \multirow[t]{3}{*}{ Knowledge of DR } & Poor & $74(52.1)$ & $52(37.1)$ & 1 & 1 & \\
\hline & Good & $55(38.7)$ & $66(47.1)$ & $0.58(0.35-0.96)$ & $0.34(0.04-2.75)$ & 0.317 \\
\hline & Excellent & $13(9.2)$ & $22(15.7)$ & $0.41(0.19-0.89)$ & $0.021(0.001-0.41)$ & 0.011 \\
\hline \multirow[t]{2}{*}{ Attitude toward DR } & Negative & 48(33.8) & $30(21.4)$ & 1.87(1.09-3.19) & $0.83(0.127-5.43)$ & 0.847 \\
\hline & Positive & $94(66.2)$ & $110(78.6)$ & 1 & 1 & \\
\hline \multirow[t]{4}{*}{ Duration of DM } & $<5$ years & $12(8.5)$ & $82(58.6)$ & $0.024(0.01-0.05)$ & $0.005(0.00-0.10)$ & $0.001^{*}$ \\
\hline & $5-10$ years & $26(18.3)$ & $31(22.1)$ & $0.136(0.06-0.30)$ & $0.041(0.003-0.57)$ & $0.018^{*}$ \\
\hline & $11-15$ years & $30(21.1)$ & 15(10.7) & $0.324(0.13-0.77)$ & $0.092(0.006-1.38)$ & 0.085 \\
\hline & $>15$ years & $74(52.1)$ & 12(8.6) & 1 & & \\
\hline \multirow[t]{2}{*}{ Glycemic control } & Good & $33(23.2)$ & 107(76.4) & 1 & 1 & \\
\hline & Poor & 109(76.8) & $33(23.6)$ & $10.7(6.17-18.58)$ & $19.9(2.34-168.69)$ & $0.006^{*}$ \\
\hline \multirow[t]{2}{*}{ SBP } & $<140 \mathrm{mmHg}$ & $40(28.2)$ & 116(82.9) & 1 & 1 & \\
\hline & $\geq 140 \mathrm{mmHg}$ & 102(71.8) & $24(17.1)$ & 12.3(6.95-21.8) & $23.4(2.56-215.36)$ & $0.005^{*}$ \\
\hline \multirow[t]{2}{*}{ Creatinine } & $>1.2 \mathrm{mg} / \mathrm{dl}$ & 73(51.4) & 44(31.4) & $2.3(1.421-3.75)$ & $3.45(0.55-21.45)$ & 0.183 \\
\hline & $\leq 1.2 \mathrm{mg} / \mathrm{dl}$ & 69(48.6) & $96(68.6)$ & 1 & 1 & \\
\hline \multirow[t]{2}{*}{ Hyperlipidemia } & Yes & $65(45.8)$ & $28(20.0)$ & $3.37(1.98-5.73)$ & $2.85(0.43-18.61)$ & 0.273 \\
\hline & No & $77(54.2)$ & 112(80.0) & 1 & 1 & \\
\hline \multirow[t]{2}{*}{ Neuropathy } & Yes & $41(28.9)$ & 25(17.9) & $1.86(1.06-3.28)$ & $3.68(0.308-44.22)$ & 0.303 \\
\hline & No & 101(71.1) & 115(82.1) & 1 & 1 & \\
\hline \multirow[t]{2}{*}{ Nephropathy } & Yes & 55(38.7) & $21(15.0)$ & $3.58(2.018-6.35)$ & $17.85(2.01-158.1)$ & $0.010^{*}$ \\
\hline & No & $87(61.3)$ & 119(85.0) & 1 & 1 & \\
\hline \multirow[t]{2}{*}{ Health information } & Yes & $23(16.2)$ & 108(77.1) & $0.057(0.03-0.10)$ & $0.002(0.00-0.042)$ & $<0.001^{*}$ \\
\hline & No & 119(83.8) & $32(22.9)$ & 1 & 1 & \\
\hline \multirow[t]{3}{*}{ Frequency of visit appointed } & Every month & 21(14.8) & 55(39.3) & $0.08(0.04-0.16)$ & $0.004(0.00-0.073)$ & $<0.001 *$ \\
\hline & Every 3 months & 25(17.6) & $65(46.4)$ & $0.08(0.041-0.15)$ & $0.022(0.002-0.23)$ & $0.002 *$ \\
\hline & Every 6 months & $96(67.6)$ & $20(14.3)$ & 1 & 1 & \\
\hline
\end{tabular}

${ }^{*}$ Significant at $P$-value $<0.05$

institutional factors that have not been addressed in previous studies.

However, this study had some limitations. Behavioral factors were collected from the current data, which may not be the same before the development of diabetic retinopathy. The lack of data on HbA1c data to measure glycemic control may affect the precision of the data. The use of self-report and review of the patient's medical records for data collection may be subject to recall bias and missing data. The study sample is institution-based, limiting the generalizability of the results to the overall Ethiopian population.

\section{Conclusions}

This study found that patients with a glucometer at home, exercise adherence, diabetes duration $<5$ years and 5-10 years, health information on diabetic complications and appointments every month and every 3 months had a decreased risk of DR; however, patients with poor glycemic control, systolic hypertension and 
nephropathy had an increased risk of DR. In light of these findings targeted intervention should be designed at follow-up clinics to address the risk group and patients should maintain lifestyle modification practices to prevent diabetic retinopathy. Further studies using robust designs such as a prospective study by incorporating large samples should be conducted to explore more about the disease's progression and assess related behavioral factors starting from the diagnosis. Further studies are needed to determine the relationship between the studied variables and specific subtypes of DR determined by severity or grade.

\section{Abbreviations}

AOR: Adjusted odds ratio; BMI: Body mass index; BUN: Blood urea nitrogen; Cl: Confidence interval; COR: Crude odds ratio; DBP: Diastolic blood pressure; DM: Diabetes mellitus; DR: Diabetic retinopathy; ETB: Ethiopian birr; FBS: Fasting blood sugar; HCPs: Health care providers; HCR-R: Revised health care relationship; SBP: Systolic blood pressure; SD: Standard deviation.

\section{Acknowledgements}

The authors sincerely thank Jimma University for providing the opportunity to conduct this research. We would also like to express our deepest gratitude to the Tikur Anbessa Hospital administrative and all staff in the diabetic clinic for their unreserved cooperation. Lastly, we thank the data collectors and all research participants who participated in the study.

\section{Authors' contributions}

KS: conception, design, data analysis, interpretation of findings, and a major contributor to writing the manuscript. $T T, A B$, and $H M$ : design, data analysis, interpretation of findings, and manuscript preparation. All authors read and approved the final manuscript.

\section{Funding}

This research was funded by the Jimma University Institute of Health. The funding body had no role in the design of the study and collection, analysis, and interpretation of data and in writing the manuscript.

\section{Availability of data and materials}

Datasets obtained or analyzed during the current study are available from the corresponding author upon reasonable request.

\section{Declarations}

\section{Ethics approval and consent to participate}

Ethical approval was obtained from the Jimma University Institute of Health Institutional Review Board prior to commencement. Further permission was obtained from the Tikur Anbessa Hospital administrative and unit heads. Confidentiality was guaranteed by excluding names or any other personal identifiers from data-collection sheets and reports. Participants were informed of the aim of the study, the advantages of the study, and their rights even to stop in the middle of the procedure. Informed consent was obtained from patients aged 18 years and above, but informed assent was obtained from patients below 18 years of age.

\section{Consent for publication}

Not applicable.

\section{Competing interests}

The authors declared that they have no competing interests.

\section{Author details}

'Department of Nursing, College of Health Science, Mizan-Tepi University, P.O. Box: 260, Mizan, SNNPR, Ethiopia. ${ }^{2}$ School of Nursing, Faculty of Health Science, Institute of Health, Jimma University, P.O. Box: 378, Jimma, Ethiopia.
${ }^{3}$ Department of Medical Laboratory Science, College of Health Science, MizanTepi University, P.O. Box: 260, Mizan, SNNPR, Ethiopia.

Received: 3 December 2020 Accepted: 16 June 2021

Published online: 30 July 2021

\section{References}

1. Prokofyeva E, Zrenner E. Epidemiology of major eye diseases leading to blindness in Europe: a literature review. Ophthalmic Res. 2012;47(4):171-88.

2. World Health Organization. Prevention of blindness from diabetes mellitus: report of a WHO consultation in Geneva, Switzerland, 9-11 November 2005. World Health Organization; 2006. https://apps.who.int/iris/handle/ $10665 / 43576$

3. Solomon SD, Chew E, Duh EJ, Sobrin L, Sun JK, VanderBeek BL, et al. Diabetic retinopathy: a position statement by the American Diabetes Association. Diabetes Care. 2017:40(3):412-8.

4. Yau JW, Rogers SL, Kawasaki R, Lamoureux EL, Kowalski JW, BekT, et al. Global prevalence and major risk factors of diabetic retinopathy. Diabetes Care. 2012;35(3):556-64.

5. Babazadeh T, Dianatinasab M, Daemi A, Nikbakht HA, Moradi F, Ghaffarifam S. Association of self-care behaviors and quality of life among patients with type 2 diabetes mellitus: Chaldoran County, Iran. Diabetes Metab J. 2017;41(6):449-56.

6. Kramer CK, Rodrigues TC, Canani LH, Gross JL, Azevedo MJ. Diabetic retinopathy predicts all-cause mortality and cardiovascular events in both type 1 and 2 diabetes. Diabetes Care. 2011;34:1238-44.

7. Ligda $\mathrm{G}$, et al. Quality of life in subjects with type 2 diabetes mellitus with diabetic retinopathy: a case econtrol study. Diabetes Metab Syndr. 2019;13:947-52.

8. Leasher JL, Bourne RR, Flaxman SR, Jonas JB, Keeffe J, Naidoo K, et al. Global estimates on the number of people blind or visually impaired by diabetic retinopathy: a meta-analysis from 1990 to 2010. Diabetes Care. 2016;39(9):1643-9.

9. Burgess Pl, et al. Epidemiology of diabetic retinopathy and maculopathy in Africa: a systematic review. Diabet Med. 2013;30:399-412.

10. Heintz E, Wiréhn AB, Peebo BB, Rosenqvist U, Levin LA. Prevalence and healthcare costs of diabetic retinopathy: a population-based register study in Sweden. Diabetologia. 2010;53(10):2147-54.

11. Baehr W, et al. Diabetic retinopathy, an overview. Vision Res. 2017;139:1-6.

12. Fite RO, et al. Diabetic retinopathy in Ethiopia: a systemic review and meta-analysis. Diabetes Metab Syndr. 2019;13(3):1885-91.

13. AMECA. Alex's medical and educational clinic in Africa. Ethiopia: Black Lion Specialized Hospital, AMECA; 2015.

14. Lechner J, O'leary OE, Stitt AW. The pathology associated with diabetic retinopathy. Vision Res. 2017;139:7-14.

15. Anwar SB, Asif N, Naqvi SAH, Malik S. Evaluation of multiple risk factors involved in the development of diabetic retinopathy. Pak J Med Sci. 2019;35(1):156-60.

16. Al-Rubeaan K, Abu El-Asrar AM, Youssef AM, Subhani SN, Ahmad NA, Al-Sharqawi AH, Alguwaihes A, Alotaibi MS, Al-Ghamdi A, Ibrahim HM. Diabetic retinopathy and its risk factors in a society with a type 2 diabetes epidemic: a Saudi National Diabetes Registry-based study. Acta Opthalmol. 2015;93:e140-7.

17. Jansson RW, Hufthammer KO, Krohn J. Diabetic retinopathy in type 1 diabetes patients in Western Norway. Acta Ophthalmol. 2018;96:465-74.

18. Chatziralli IP. The role of glycemic control and variability in diabetic retinopathy. Diabetes Ther. 2018;9:431-4.

19. Tilahun AN, Waqtola C, Tewodros GM, Amare DW, Yohannis M. Major micro vascular complications and associated risk factors among diabetic outpatients in Southwest Ethiopia. Endocrinol Metab Syndr. 2017;6(4):272.

20. Azeze, et al. Incidence of diabetes retinopathy and determinants of time to diabetes retinopathy among diabetes patients at Tikur Anbessa Hospital, Ethiopia: a retrospective follow up study. BMC Res Notes. 2018;11:542.

21. Tsion Shibru, Fekadu Aga, Abdisa Bok. Prevalence of Diabetic Retinopathy and Associated Factors among Type 2 Diabetes Patients at Tikur Anbessa Hospital, Ethiopia. J Diabetes Metab. 2019;10:820. https://doi.org/10. 35248/2155-6156.19.10.820. 
22. Al-Asbali T, Aldawari SA, Alzahim IA, Alalawi H, Khandekar R, Lotfy NM. Knowledge, attitude and practice regarding diabetic retinopathy screening and its management among diabetic patients at a private hospital of Riyadh, Saudi Arabia. Saudi J Ophthalmol. 2020;34(2):85-93. https://doi. org/10.4103/1319-4534.305040.

23. Bova C, Route PS, Fennie K, Ettinger W, Manchester GW, Weinstein B. Measuring patient-provider trust in a primary care population: refinement of the health care relationship trust scale. Res Nurs Health. 2012;35(4):397-408

24. Ting DS, Cheung GC, Wong TY. Diabetic retinopathy: global prevalence, major risk factors, screening practices and public health challenges: a review. Clin Exp Ophthalmol. 2016;44(4):260-77.

25. Hinkle JL, Cheever KH. Brunner \& Suddarth's textbook of medical-surgical nursing. 14th ed. Philadelphia: Wolters Kluwer; 2018.

26. CDC. National Heath and Nutrition Examnation Survey (NHANES) anthropometry procedures manual. 2007.

27. World Health Organization, Manual of Operations P and C of CL, Philippines ND in the. Risk factors assessment and screening procedures. In: Training mannual. 2009.

28. WHO. Definition and diagnosis of Diabetes Mellitus and intermediate hyperglycemia. 2006.

29. Praidou A, Harris M, Niakas D, Labiris G. Physical activity and its correlation to diabetic retinopathy. J Diabetes Complications. 2017;31(2):456-61.

30. Lima VC, Cavalieri GC, Lima MC, Nazario NO, Lima GC. Risk factors for diabetic retinopathy: a case-control study. Int J Retina Vitreous. 2016;2(1):1-7.

31. Martín-Merino E, Fortuny J, Rivero-Ferrer E, Lind M, Garcia-Rodriguez LA. Risk factors for diabetic retinopathy in people with type 2 diabetes: a case-control study in a UK primary care setting. Prim Care Diabetes. 2016;10(4):300-8.

32. Nittala MG, Keane PA, Zhang K, Sadda SR. Risk factors for proliferative diabetic retinopathy in a Latino American population. Retina (Philadelphia, Pa). 2014;34(8):1594.

33. Penman A, Hancock H, Papavasileiou E, James M, Idowu O, Riche DM, et al. Risk factors for proliferative diabetic retinopathy in African Americans with type 2 diabetes. Ophthalmic Epidemiol. 2016;23(2):88-93.

34. Cleland CR, et al. Diabetic retinopathy in Tanzania: prevalence and risk factors at entry into a regional screening programme. Trop Med Int Health. 2016;21(3):417-26.
35. Rasoulinejad SA, Hajian-Tilaki K, Mehdipour E. Associated factors of diabetic retinopathy in patients that referred to teaching hospitals in Babol. Caspian J Intern Med. 2015;6(4):224

36. Goyal M, Kamboj P, Behgal J, Rathee S, Lather T. Risk factors of diabetic retinopathy in patients with type 2 diabetes mellitus. Diabetes Manage. 2017;7(6):408-11

37. Chisha Y, Terefe W, Assefa H. Incidence and factors associated with diabetic retinopathy among diabetic patients at arbaminch general hospital, gamo gofa Zone (longitudinal follow up data analysis). J Diabetol. 2017;8:1-6.

38. Nabais C, Pereira J, Pereira P, Capote R, Morbeck S, Raposo J. Diabetic retinopathy and associated conditions, what relations hip? A study in Portuguese patients with type 2 diabetes. Acta Med Port. 2011;24:71-8.

39. Chaveepojnkamjorn W, Somjit P, Rattanamongkolgul S, Siri S, Pichainarong N. Factors associated with diabetic retinopathy among type 2 diabetic patients: a hospital based case-control study. Southeast Asian J Trop Med Public Health. 2015;46(2):322.

40. Garoma D, Merga H, Hiko D. Determinants of diabetic retinopathy in Southwest Ethiopia: a facility-based case-control study. BMC Public Health. 2020:20:1-9.

41. Klaassen I, Van Noorden CJ, Schlingemann RO. Molecular basis of the inner blood-retinal barrier and its breakdown in diabetic macular edema and other pathological conditions. Prog Retin Eye Res. 2013;34:19-48.

42. Chisha Y, Terefe W, Assefa H, Lakew S. Prevalence and factors associated with diabetic retinopathy among diabetic patients at Arbaminch General Hospital, Ethiopia: cross sectional study. PLoS One. 2017;12(3):e0171987.

43. Qiu C, Cotch MF, Sigurdsson S, Garcia M, Klein R, Jonasson F. Retinal and cerebral microvascular signs and diabetes: the age, gene/environment susceptibility—Reykjavik study. Diabetes. 2008;57(6):1645-50.

44. Shrivastava SR, Shrivastava PS, Ramasamy J. Role of self-care in management of diabetes mellitus. J Diabetes Metab Disord. 2013;12(1):14.

\section{Publisher's Note}

Springer Nature remains neutral with regard to jurisdictional claims in published maps and institutional affiliations.
Ready to submit your research? Choose BMC and benefit from:

- fast, convenient online submission

- thorough peer review by experienced researchers in your field

- rapid publication on acceptance

- support for research data, including large and complex data types

- gold Open Access which fosters wider collaboration and increased citations

- maximum visibility for your research: over 100M website views per year

At $B M C$, research is always in progress.

Learn more biomedcentral.com/submissions 